\title{
A new variant of statistical convergence
}

\author{
Syed Abdul Mohiuddine ${ }^{1}$, Abdullah Alotaibi' and Mohammad Mursaleen ${ }^{2 *}$
}

"Correspondence:

mursaleenm@gmail.com

2 Department of Mathematics, Aligarh Muslim University, Aligarh, 202002, India

Full list of author information is available at the end of the article

\begin{abstract}
In this paper we study the notion of statistical $(A, \lambda)$-summability, which is a generalization of statistical $A$-summability. We study here many other related concepts and its relations with statistical convergence and $\lambda$-statistical convergence and provide some interesting examples.
\end{abstract}

Keywords: density; statistical convergence; de la Vallée-Poussin; regular matrix

\section{Introduction and preliminaries}

The concept of statistical convergence was first introduced by Fast [1]. In 1953 the concept arose as an example of convergence in density as introduced by Buck [2]. Schoenberg [3] studied statistical convergence as a summability method and Zygmund [4] established a relation between it and strong summability. This idea has grown a little faster after the papers of Šalát [5] , Fridy [6] , Connor [7, 8], Kolk [9], Mursaleen [10], Mursaleen and Edely $[11,12]$, Mursaleen and Mohiuddine [13-17] and many others. Its various generalizations, extensions and variants have been studied by various authors so far. For example, lacunary statistical convergence [18], $\lambda$-statistical convergence $[10,19-21], A$-statistical convergence [9], statistical summability $(C, 1)[22-24]$; statistical $\lambda$-summability [25], statistical lacunary summability [26], statistical $A$-summability [27] etc. For more details, related concepts and applications, we refer to [28-41] and references therein. Here we define the notion of statistical $(A, \lambda)$-summability as a $\lambda$-statistical convergence of $A$-transform of $x$ and prove some results on some related sets of sequences. The results of this paper extend several ones obtained up to now and establish several inclusion relations, implications and other properties.

Let $K \subseteq \mathbb{N}$, the set of natural numbers. Then the natural density of $K$ is defined by

$$
\delta(K)=\lim _{n} \frac{1}{n}|\{k \leq n: k \in K\}|
$$

if the limit exists, where the vertical bars denote the cardinality of the enclosed set.

The idea of $\lambda$-statistical convergence was introduced in [10] as follows:

Let $\lambda=\left(\lambda_{n}\right)$ be a non-decreasing sequence of positive numbers tending to $\infty$ such that

$$
\lambda_{n+1} \leq \lambda_{n}+1, \quad \lambda_{1}=0
$$

(c) 2013 Mohiuddine et al.; licensee Springer. This is an Open Access article distributed under the terms of the Creative Commons Attribution License (http://creativecommons.org/licenses/by/2.0), which permits unrestricted use, distribution, and reproduction in any medium, provided the original work is properly cited. 
The generalized de la Vallée-Poussin mean is defined by

$$
t_{n}(x)=: \frac{1}{\lambda_{n}} \sum_{j \in I_{n}} x_{j}
$$

where $I_{n}=\left[n-\lambda_{n}+1, n\right]$.

Let $K \subseteq \mathbb{N}$. Then

$$
\delta_{\lambda}(K)=\lim _{n} \frac{1}{\lambda_{n}}\left|\left\{n-\lambda_{n}+1 \leq j \leq n: j \in K\right\}\right|
$$

is said to be $\lambda$-density of $K$.

In case $\lambda_{n}=n, \lambda$-density reduces to the natural density. Also, since $\left(\lambda_{n} / n\right) \leq 1, \delta(K) \leq$ $\delta_{\lambda}(K)$ for every $K \subseteq \mathbb{N}$.

A sequence $x=\left(x_{k}\right)$ is said to be $\lambda$-statistically convergent to $L$ if for every $\epsilon>0$ the set $K_{\epsilon}:=\left\{k \in \mathbb{N}:\left|x_{k}-L\right| \geq \epsilon\right\}$ has $\lambda$-density zero, i.e., $\delta_{\lambda}\left(K_{\epsilon}\right)=0$. That is,

$$
\lim _{n} \frac{1}{\lambda_{n}}\left|\left\{n-\lambda_{n}+1 \leq j \leq n:\left|x_{k}-L\right| \geq \epsilon\right\}\right|=0 .
$$

In this case we write $s t_{\lambda}-\lim x=L$.

Let $A=\left(a_{n k}\right)$ be an infinite matrix of real or complex numbers and $x=\left(x_{k}\right)$ be a sequence of real or complex numbers. Then we write $A_{n}(x)=\sum_{k=1}^{\infty} a_{n k} x_{k}$, which is called the $A$ transform of the sequence $x=\left(x_{k}\right)$ whenever the series on the right converges for each $n=1,2, \ldots$.

We assume throughout this paper that the symbols $\omega$ and $c$ denote the spaces of all sequences (real or complex numbers) and the space of all convergent sequences, respectively. Let $X$ and $Y$ be two nonempty subsets of the space $\omega$. If $x \in X$ implies $A x=\left(A_{n}(x)\right) \in Y$, then we say that $A$ defines a matrix transformation from $X$ into $Y$, and we denote by $(X, Y)$ the class of matrices $A$ which transform $X$ into $Y$. By $(X, Y)_{\text {reg }}$ we denote the subset of $(X, Y)$ for which limit or sum is preserved.

A matrix $A=\left(a_{n k}\right)$ is said to be conservative if $A x \in c$ for $x=\left(x_{k}\right) \in c$, and we denote this by $A \in(c, c)$.

A matrix $A=\left(a_{n k}\right)$ is said to be regular if it is conservative and $\lim A x=\lim x$, and we denote this by $A \in(c, c)_{\text {reg. }}$.

The following are well-known Silverman-Toeplitz [42] conditions for the regularity of $A$.

A matrix $A=\left(a_{n k}\right)$ is regular, i.e., $A \in(c, c)_{\text {reg }}$ if and only if

(i) $\sup _{n} \sum_{k}\left|a_{n k}\right|<\infty$;

(ii) $\lim _{n \rightarrow \infty} a_{n k}=0$, for each $k$;

(iii) $\lim _{n \rightarrow \infty} \sum_{k} a_{n k}=1$.

Let $A=\left(a_{i j}\right)$ be a non-negative regular matrix. A sequence $x$ is said to be statistically $A$-summable to $L$ if, for every $\epsilon>0, \delta\left(\left\{i \leq n:\left|y_{i}-L\right| \geq \epsilon\right\}\right)=0$, i.e.,

$$
\lim _{n} \frac{1}{n}\left|\left\{i \leq n:\left|y_{i}-L\right| \geq \epsilon\right\}\right|=0,
$$

where $y_{i}=A_{i}(x)$. Thus $x$ is statistically $A$-summable to $L$ if and only if $A x$ is statistically convergent to $L$. In this case we write $L=(A)_{s t}-\lim x=s t$ - $\lim A x$. 


\section{Statistical $(A, \lambda)$-summability}

In [43], Malafosse and Rakočević presented the following definition of statistically $(A, \lambda)$ summable.

Definition 2.1 A sequence $x$ is said to be statistically $(A, \lambda)$-summable to $L$ if for every $\epsilon>0, \delta_{\lambda}\left(\left\{n-\lambda_{n}+1 \leq i \leq n:\left|y_{i}-L\right| \geq \epsilon\right\}\right)=0$, i.e.,

$$
\lim _{n} \frac{1}{\lambda_{n}}\left|\left\{n-\lambda_{n}+1 \leq i \leq n:\left|y_{i}-L\right| \geq \epsilon\right\}\right|=0 .
$$

Thus $x$ is statistically $(A, \lambda)$-summable to $L$ if and only if $A x$ is $\lambda$-statistically convergent to $L$. In this case we write $L=(A, \lambda)_{s t}-\lim x=s t_{\lambda}-\lim A x$. By $(A, \lambda)_{s t}$ we denote the set of all statistically $(A, \lambda)$-summable sequences.

We define the following.

Definition 2.2 A sequence $x=\left(x_{k}\right)$ is said to be strongly $\left(A, \lambda_{q}\right)$-convergent $(0<q<\infty)$ to the limit $L$ if $\lim _{n} \frac{1}{\lambda_{n}} \sum_{i \in I_{n}}\left|y_{i}-L\right|^{q}=0$, and we write it as $x_{k} \longrightarrow L[A, \lambda]_{q}$. In this case $L$ is called the $[A, \lambda]_{q}$-limit of $x$.

\section{Remarks 2.3}

(i) If $A=I$ (the unit matrix), then the statistical $(A, \lambda)$-summability is reduced to the $\lambda$-statistical convergence.

(ii) If $\lambda_{n}=n$, then the statistical $(A, \lambda)$-summability is reduced to the statistical $A$-summability.

(iii) If $\lambda_{n}=n$ and

$$
a_{i k}= \begin{cases}\frac{1}{i+1}, & 0 \leq k \leq i, \\ 0, & \text { otherwise }\end{cases}
$$

then the statistical $(A, \lambda)$-summability is reduced to the statistical $(C, 1)$-summability due to Moricz [22].

(iv) If $\lambda_{n}=n$ and

$$
a_{i k}= \begin{cases}\frac{p_{k}}{P_{i},} & 0 \leq k \leq i \\ 0, & \text { otherwise }\end{cases}
$$

then the statistical $(A, \lambda)$-summability is reduced to the statistical $(\bar{N}, p)$-summability due to Moricz and Orhan [44], where $p=\left(p_{k}\right)$ is a sequence of nonnegative numbers such that $p_{0}>0$ and

$$
P_{i}=\sum_{k=0}^{i} p_{k} \rightarrow \infty \quad(i \rightarrow \infty) .
$$

(v) If $\lambda_{n}=n$ and

$$
a_{i k}= \begin{cases}\frac{1}{k l_{i}}, & 0 \leq k \leq i \\ 0, & \text { otherwise }\end{cases}
$$


where $l_{i}=\sum_{k=0}^{i} \frac{1}{(k+1)}$, then the statistical $(A, \lambda)$-summability is reduced to the statistical $(H, 1)$-summability due to Moricz [45].

\section{Main results}

In this section, we establish the relation between statistical $(A, \lambda)$-summability and $A$-statistical convergence.

Theorem 3.1 If a bounded sequence is A-statistically convergent to $\ell$ and $\liminf _{n \rightarrow \infty} \frac{\lambda_{n}}{n}>$ 0 , then it is $A$ summable to $\ell$, statistically $A$-summable to $\ell$, and hence statistically $(A, \lambda)$ summable to $\ell$ but not conversely.

Proof Let $x$ be bounded and $A$-statistically convergent to $L$, and $K_{\epsilon}=\left\{k \leq n:\left|x_{k}-L\right| \geq \epsilon\right\}$. Then

$$
\begin{aligned}
\left|A_{n}(x)-L\right| & =\left|\sum_{k=1}^{\infty} a_{n k}\left(x_{k}-L\right)+L\left(\sum_{k=1}^{\infty} a_{n k}-1\right)\right| \\
& \leq \sum_{k=1}^{\infty} a_{n k}\left|x_{k}-L\right|+|L|\left|\sum_{k=1}^{\infty} a_{n k}-1\right| \\
& =\sum_{k \in K_{\epsilon}} a_{n k}\left|x_{k}-L\right|+\sum_{k \notin K_{\epsilon}} a_{n k}\left|x_{k}-L\right|+|L|\left|\sum_{k=1}^{\infty} a_{n k}-1\right| \\
& \leq \sup _{k}\left|x_{k}-L\right| \sum_{k \in K_{\epsilon}} a_{n k}+\epsilon \sum_{k \notin K_{\epsilon}} a_{n k}+|L|\left|\sum_{k=1}^{\infty} a_{n k}-1\right| .
\end{aligned}
$$

By using the definition of $A$-statistical convergence and the conditions of regularity of $A$, we get

$$
\lim \left|A_{n}(x)-L\right|=0 \quad \text { since } \epsilon \text { was arbitrary, }
$$

and hence $s t$ - $\lim \left|A_{n}(x)-L\right|=0$, i.e., $x$ is statistically $A$-summable to $L$. Now, using Theorem 3.1 of [10], we get $s t_{\lambda}-\lim \left|A_{n}(x)-L\right|=0$, i.e., $x$ is statistically $(A, \lambda)$-summable to $L$.

To see that the converse does not hold, we construct the following example.

Let $\lambda_{n}=n$ and $A$ be a Cesàro matrix, i.e.,

$$
a_{n k}= \begin{cases}\frac{1}{n+1}, & 0 \leq n \leq k \\ 0, & \text { otherwise. }\end{cases}
$$

Let

$$
x_{k}= \begin{cases}1, & \text { if } k \text { is odd } \\ 0, & \text { if } k \text { is even }\end{cases}
$$

Then $x$ is $A$-summable to $1 / 2$ (and hence statistically $(A, \lambda)$-summable to $1 / 2$ ) but not $A$-statistically convergent.

This completes the proof of the theorem. 
Theorem 3.2 If $\lim \sup _{n}\left(n-\lambda_{n}\right)<\infty$ and $x$ is statistically $(A, \lambda)$-summable to L, then $x$ is statistically A-summable to $L$.

Proof Let $\lim \sup _{n}\left(n-\lambda_{n}\right)<\infty$. Then there exists $M>0$ such that $n-\lambda_{n} \leq M$ for all $n$. Since $\frac{1}{n} \leq \frac{1}{\lambda_{n}}$ and

$$
\left\{1 \leq i \leq n:\left|y_{i}-L\right| \geq \varepsilon\right\} \subseteq\left\{i \in I_{n}:\left|y_{i}-L\right| \geq \varepsilon\right\} \cup\left\{1 \leq i \leq n-\lambda_{n}:\left|y_{i}-L\right| \geq \varepsilon\right\},
$$

we have

$$
\begin{aligned}
& \frac{1}{n}\left|\left\{1 \leq i \leq n:\left|y_{i}-L\right| \geq \varepsilon\right\}\right| \\
& \quad \leq \frac{1}{\lambda_{n}}\left|\left\{1 \leq i \leq n:\left|y_{i}-L\right| \geq \varepsilon\right\}\right| \\
& \quad \leq \frac{1}{\lambda_{n}}\left|\left\{i \in I_{n}:\left|y_{i}-L\right| \geq \varepsilon\right\}\right|+\frac{1}{\lambda_{n}}\left|\left\{i \leq n-\lambda_{n}:\left|y_{i}-L\right| \geq \varepsilon\right\}\right| \\
& \quad \leq \frac{1}{\lambda_{n}}\left|\left\{i \in I_{n}:\left|y_{i}-L\right| \geq \varepsilon\right\}\right|+\frac{M}{\lambda_{n}} .
\end{aligned}
$$

Now, taking the limit as $n \rightarrow \infty$, we get the desired result.

Theorem 3.3 Statistical $(A, \lambda)$-summability implies statistical A-summability if and only if

$$
\lim _{n \rightarrow \infty} \frac{\lambda_{n}}{n}>0 .
$$

Proof For $\varepsilon>0$, we have

$$
\left\{i \in I_{n}:\left|y_{i}-L\right| \geq \varepsilon\right\} \subset\left\{i \leq n:\left|y_{i}-L\right| \geq \varepsilon\right\} .
$$

Therefore

$$
\begin{aligned}
\frac{1}{n}\left|\left\{i \leq n:\left|y_{i}-L\right| \geq \varepsilon\right\}\right| & \geq \frac{1}{n}\left|\left\{i \in I_{n}:\left|y_{i}-L\right| \geq \varepsilon\right\}\right| \\
& \geq \frac{\lambda_{n}}{n} \cdot \frac{1}{\lambda_{n}}\left|\left\{i \in I_{n}:\left|y_{i}-L\right| \geq \varepsilon\right\}\right| .
\end{aligned}
$$

Taking the limit as $n \rightarrow \infty$ and using (3.1), we get that statistical $(A, \lambda)$-summability implies statistical $A$-summability.

Conversely, suppose that

$$
\lim _{n \rightarrow \infty} \frac{\lambda_{n}}{n}=0 .
$$

Choose a subsequence $(n(j))_{j \geq 1}$ such that $\frac{\lambda_{n(j)}}{n(j)}<\frac{1}{j}$. Define a sequence $x=\left(x_{k}\right)_{k \geq 1}$ such that

$$
y_{i}= \begin{cases}1, & \text { for } i \in I_{n(j)}, j=1,2,3, \ldots \\ 0, & \text { otherwise. }\end{cases}
$$


Then, as in Theorem 3.1 of [10], we get that $y=\left(y_{i}\right)$ is not $\lambda$-statistically convergent, i.e., $x$ is not statistically $(A, \lambda)$-summable. Hence (3.1) is necessary.

This completes the proof of the theorem.

Theorem 3.4 (a) If $0<q<\infty$ and a sequence $x=\left(x_{k}\right)$ is strongly $\left(A, \lambda_{q}\right)$-convergent to the limit $L$, then $x$ is statistically $(A, \lambda)$-convergent to $L$.

(b) If $x=\left(x_{k}\right)$ is bounded and statistically $(A, \lambda)$-convergent to $L$, then $x_{k} \rightarrow L[A, \lambda]_{q}$.

Proof (a) It follows easily from the following:

$$
\frac{1}{\lambda_{n}} \sum_{i \in I_{n}}\left|y_{i}-L\right|^{q} \geq \frac{\varepsilon^{q}}{\lambda_{n}}\left|\left\{i \in I_{n}:\left|y_{i}-L\right| \geq \varepsilon\right\}\right| .
$$

The following example shows that the inclusion is proper. Let $x=\left(x_{n}\right)_{n \geq 1}$ be such that its $A$-transform is given by

$$
y_{i}= \begin{cases}i, & \text { for } n-\left[\sqrt{\lambda_{n}}\right]+1 \leq i \leq n, \\ 0, & \text { otherwise }\end{cases}
$$

Then $A x \notin \ell_{\infty}$ and for $0<\varepsilon \leq 1$,

$$
\frac{1}{\lambda_{n}}\left|\left\{i \in I_{n}:\left|y_{i}-0\right| \geq \varepsilon\right\}\right|=\frac{\left[\sqrt{\lambda_{n}}\right]}{\lambda_{n}} \rightarrow 0 \quad(n \rightarrow \infty),
$$

i.e., $x$ is statistically $(A, \lambda)$-convergent to 0 . But

$$
\frac{1}{\lambda_{n}} \sum_{i \in I_{n}}\left|y_{i}-0\right|^{q} \nrightarrow 0
$$

i.e., $x$ is not strongly $\left(A, \lambda_{q}\right)$-convergent to the limit 0 .

(b) Suppose $x=\left(x_{k}\right)$ is bounded and statistically $(A, \lambda)$-convergent to $L$. Then $\left|x_{k}-L\right| \leq$ $M$ for all $k$, where $M>0$. For $\varepsilon>0$, we have

$$
\begin{aligned}
\frac{1}{\lambda_{n}} \sum_{k \in I_{n}}\left|y_{i}-L\right|^{q} & =\frac{1}{\lambda_{n}} \sum_{\substack{i \in I_{n} \\
\left|y_{i}-L\right|^{q} \geq \epsilon}}\left|y_{i}-L\right|^{q}+\frac{1}{\lambda_{n}} \sum_{\substack{i \in I_{n} \\
\left|y_{i}-L\right|^{q}<\epsilon}}\left|y_{i}-L\right|^{q} \\
& \leq \frac{M}{\lambda_{n}}\left|\left\{i \in I_{n}:\left|y_{i}-L\right| \geq \varepsilon\right\}\right|+\varepsilon^{q} .
\end{aligned}
$$

Hence $x_{k} \longrightarrow L[A, \lambda]_{q}$ if $x$ is statistically $(A, \lambda)$-convergent to $L$.

This completes the proof of the theorem.

\section{Competing interests}

The authors declare that they have no competing interests.

\section{Authors' contributions}

The authors contributed equally and significantly in writing this paper. All the authors read and approved the final manuscript. 


\section{Author details}

1 Department of Mathematics, Faculty of Science, King Abdulaziz University, P.O. Box 80203, Jeddah, 21589, Saudi Arabia.

${ }^{2}$ Department of Mathematics, Aligarh Muslim University, Aligarh, 202002, India.

\section{Acknowledgements}

This project was funded by the Deanship of Scientific Research (DSR), King Abdulaziz University, Jeddah, under grant No. (334/130/1433). The authors, therefore, acknowledge with thanks DSR technical and financial support.

\section{Received: 27 March 2013 Accepted: 13 June 2013 Published: 3 July 2013}

\section{References}

1. Fast, H: Sur la convergence statistique. Colloq. Math. 2, 241-244 (1951)

2. Buck, RC: Generalized asymptotic density. Am. J. Math. 75, 335-346 (1953)

3. Schoenberg, IJ: The integrability of certain functions and related summability methods. Am. Math. Mon. 66, 361-375 (1959)

4. Zygmund, A: Trigonometric Series. Cambridge University Press, Cambridge (1959)

5. Šalát, T: On statistically convergent sequences of real numbers. Math. Slovaca 30, 139-150 (1980)

6. Fridy, JA: On statistical convergence. Analysis 5, 301-313 (1985)

7. Connor, J: The statistical and strong $p$-Cesàro convergence of sequences. Analysis 8, 47-63 (1988)

8. Connor, J: On strong matrix summability with respect to a modulus and statistical convergence. Can. Math. Bull. 32 194-198 (1989)

9. Kolk, E: Matrix summability of statistically convergent sequences. Analysis 13, 77-83 (1993)

10. Mursaleen, $\mathrm{M}$ : $\lambda$-statistical convergence. Math. Slovaca 50,111-115 (2000)

11. Mursaleen, M, Edely, OHH: Statistical convergence of double sequences. J. Math. Anal. Appl. 288, $223-231$ (2003)

12. Mursaleen, M, Edely, OHH: Generalized statistical convergence. Inf. Sci. 162, 287-294 (2004)

13. Mursaleen, M, Mohiuddine, SA: Statistical convergence of double sequences in intuitionistic fuzzy normed spaces. Chaos Solitons Fractals 41, 2414-2421 (2009)

14. Mursaleen, M, Mohiuddine, SA: On lacunary statistical convergence with respect to the intuitionistic fuzzy normed space. J. Comput. Appl. Math. 233(2), 142-149 (2009)

15. Mursaleen, M, Mohiuddine, SA: On ideal convergence of double sequences in probabilistic normed spaces. Mathem. Rep. (Buchar.) 12(4), 359-371 (2010)

16. Mursaleen, $\mathrm{M}$, Mohiuddine, $\mathrm{SA}$, Edely, $\mathrm{OHH}$ : On the ideal convergence of double sequences in intuitionistic fuzzy normed spaces. Comput. Math. Appl. 59, 603-611 (2010)

17. Mursaleen, M, Mohiuddine, SA: On ideal convergence in probabilistic normed spaces. Math. Slovaca 62(1), 49-62 (2012)

18. Fridy, JA, Orhan, C: Lacunary statistical convergence. Pac. J. Math. 160, 43-51 (1993)

19. Edely, OHH, Mohiuddine, SA, Noman, AK: Korovkin type approximation theorems obtained through generalized statistical convergence. Appl. Math. Lett. 23, 1382-1387 (2010)

20. Savaş, E, Mohiuddine, SA: $\bar{\lambda}$-statistically convergent double sequences in probabilistic normed spaces. Math. Slovaca 62(1), 99-108 (2012)

21. Mohiuddine, SA, Alotaibi, A, Mursaleen, M: Statistical convergence through de la Vallée-Poussin mean in locally solid Riesz spaces. Adv. Differ. Equ. 2013, Article ID 66 (2013)

22. Moricz, F: Tauberian conditions under which statistical convergence follows from statistical summability $(C, 1)$. J. Math. Anal. Appl. 275, 277-287 (2002)

23. Mohiuddine, SA, Alotaibi, A, Mursaleen, M: Statistical summability $(C, 1)$ and a Korovkin type approximation theorem. J. Inequal. Appl. 2012, Article ID 172 (2012)

24. Mohiuddine, SA, Alotaibi, A: Korovkin second theorem via statistical summability (C, 1). J. Inequal. Appl. 2013, Article ID 149 (2013)

25. Mursaleen, M, Alotaibi, A: Statistical summability and approximation by de la Vallée-Poussin mean. Appl. Math. Lett. 24, 320-324 (2011). (Erratum: Appl. Math. Lett. 25, 665 (2012))

26. Mursaleen, M, Alotaibi, A: Statistical lacunary summability and a Korovkin type approximation theorem. Ann. Univ. Ferrara, Sez. 7: Sci. Mat. 57(2), 373-381 (2011)

27. Edely, $\mathrm{OHH}$, Mursaleen, M: On statistical A-summability. Math. Comput. Model. 49, 672-680 (2009)

28. Alotaibi, A, Mursaleen, M: A-statistical summability of Fourier series and Walsh-Fourier series. Appl. Math. Inf. Sci. 6(3), 535-538 (2012)

29. Freedman, AR, Sember, JJ: Densities and summability. Pac. J. Math. 95, 293-305 (1981)

30. Fridy, JA, Miller, HI: A matrix characterization of statistical convergence. Analysis 11, 59-66 (1991)

31. Mohiuddine, SA, Alghamdi, MA: Statistical summability through a lacunary sequence in locally solid Riesz spaces. J. Inequal. Appl. 2012, Article ID 225 (2012)

32. Mohiuddine, SA, Aiyub, M: Lacunary statistical convergence in random 2-normed spaces. Appl. Math. Inf. Sci. 6(3), 581-585 (2012)

33. Mohuiddine, SA, Alotaibi, A, Alsulami, SM: Ideal convergence of double sequences in random 2-normed spaces. Adv. Differ. Equ. 2012, Article ID 149 (2012)

34. Mohiuddine, SA, Alotaibi, A, Mursaleen, M: Statistical convergence of double sequences in locally solid Riesz spaces. Abstr. Appl. Anal. 2012, Article ID 719729 (2012)

35. Mohiuddine, SA, Danish Lohani, QM: On generalized statistical convergence in intuitionistic fuzzy normed space. Chaos Solitons Fractals 42, 1731-1737 (2009)

36. Mohiuddine, SA, Savas, E: Lacunary statistical convergent double sequences in probabilistic normed spaces. Ann. Univ. Ferrara 58, 331-339 (2012)

37. Mohiuddine, SA, Sevli, H, Cancan, M: Statistical convergence in fuzzy 2-normed space. J. Comput. Anal. Appl. 12(4)، 787-798 (2010)

38. Mohiuddine, SA, Sevli, H, Cancan, M: Statistical convergence of double sequences in fuzzy normed spaces. Filomat 26(4), 673-681 (2012) 
39. Belen, C, Mohiuddine, SA: Generalized weighted statistical convergence and application. Appl. Math. Comput. 219 9821-9826 (2013)

40. Mohiuddine, SA, Alotaibi, A: Statistical convergence and approximation theorems for functions of two variables. J. Comput. Anal. Appl. 15(2), 218-223 (2013)

41. Mohiuddine, SA, Hazarika, B, Alotaibi, A: Double lacunary density and some inclusion results in locally solid Riesz spaces. Abstr. Appl. Anal. 2013, Article ID 507962 (2013)

42. Cooke, RG: Infinite Matrices and Sequence Spaces. Macmillan \& Co., London (1950)

43. de Malafosse, B, Rakočević, V: Matrix transformation and statistical convergence. Linear Algebra Appl. 420, 377-387 (2007)

44. Moricz, F, Orhan, C: Tauberian conditions under which statistical convergence follows from statistical summability by weighted means. Studia Sci. Math. Hung. 41(4), 391-403 (2004)

45. Moricz, F: Theorems related to statistical harmonic summability and ordinary convergence of slowly decreasing or oscillating sequences. Analysis 24, 127-145 (2004)

doi:10.1186/1029-242X-2013-309

Cite this article as: Mohiuddine et al.: A new variant of statistical convergence. Journal of Inequalities and Applications $20132013: 309$

\section{Submit your manuscript to a SpringerOpen ${ }^{\circ}$ journal and benefit from:}

- Convenient online submission

- Rigorous peer review

- Immediate publication on acceptance

- Open access: articles freely available online

- High visibility within the field

- Retaining the copyright to your article 